Biannual Research Journal Grassroots

Vol.55, No.I, 2021: 145-158

Grassroots

\title{
ANALYZING THE IMPACT OF LADY HEALTH WORKER PROGRAM ON UTILIZATION OF MATERNAL HEALTH SERVICES IN SINDH
}

\author{
Dr.Ghulam Rasool Shah \\ Chief Finance \& Accounts Officer, \\ Ministry of Information \& Broadcasting, Islamabad \\ Email:grshah61@yahoo.com \\ Dr.Ghulam Ali Jariko \\ Professor, Abida Taherani Sindh Development Studies Centre (SDSC) \\ University of Sindh Jamshoro, Pakistan \\ Email: ghulama.jariko@usindh.edu.pk
}

\begin{abstract}
The study aims to analyze impact of Lady Health Worker program on use of maternal health services in communities where lady health workers are providing services at doorsteps. The study's main focus was the rural districts of Sindh. The maternal health service is determined by at least four Antenatal care (ANC) visits provided to mother and receipt of at least two Tetanus Toxoid (TT) injections to mother during pregnancy by a Lady Health Worker(LHW). Thus effective maternal health service provision has direct impact on reducing maternal and infant mortality rate. For analysis purpose three years (2017-2019) secondary data pertaining to all districts of Sind was collected from the Sindh Lady Health Worker program head office Hyderabad. Also secondary data of Pakistan Demographic and Health Survey (2017-18) was used to see the impact of intervention of LHW program on maternal health. The LHW program was implemented by Ministry of Health, Government of Pakistan in 1994 and then devolved to provinces after implementation of the $18^{\text {th }}$ Constitutional Amendment in 2010. The study revealed that the services provided by the lady health workers in communities in these districts has positively influenced the uptake of maternal health services as determined by the dependent variables like antenatal visits by pregnant mothers to nearest health facilities and receipt of Tetanus Toxoid injection during pregnancy.
\end{abstract}

Keywords: Lady Health Worker program, Maternal Health Service, Antenatal Care, Tetanus Toxoid, Maternal Mortality Rate, Infant Mortality Rate.

\section{INTRODUCTION}

Pakistan is currently facing significant economic and governance issues, further being a lower-middle income country is still striving hard to achieve economic sustainability. General economic 
indicators are also not satisfactory. It has witnessed increase in debt burden with a fiscal deficit of $8 \%$ of the GDP. The growth rate of country though recovered to $3.4 \%$ but not at par with peer and neighboring countries, rather far behind. The Human Development Index ranks Pakistan at number 146 out of 187 countries and $22.3 \%$ of its population is living below the poverty line. The gender inequality in sectors like education, health, environment and developmental sectors has been seen with female workforce participation ratio of $22.7 \%$ as compared to $83.3 \%$ for male. Only $18.3 \%$ of women have a secondary or higher education (Rifat Atun, Nina Zhu \& Elizabeth Allen, 2014).

Pakistan's maternal and child healthcare data is upsetting too. Demographic and Health Survey Pakistan, 2017-18 depicts infant mortality rate (IMR) of 74 per 1000 live births. In rural areas the low contraceptive prevalence rate (CPR) of $25 \%$ and high fertility rate of 3.6 children per woman has hindered achievement of Sustainable Development Goals (SDGs). Thus improvement in health of mothers and children in Pakistan is of prime importance as witnessed by most of the developing countries. Pakistan Economic Survey 2017-18 depicts maternal mortality ratio (MMR) of 178 per 100,000 which has reduced from 286 in 2006-07. If maternal healthcare services are utilized effectively it can help in reducing MMR and IMR in rural areas where mostly these services are under utilized by the target population (Amin, 2010).

To improve utilization of maternal health and family planning services and make them easily accessible to poor people, Government of Pakistan (GoP) initiated the Lady Health Worker (LHW) Program in 1994. Main objectives of the LHW program were to improve uptake of Maternal and Child Health $(\mathrm{MCH})$ services in rural-slum / rural communities and promote adoption of family planning methods and distribution of effective contraceptives. It has been a big Community Based Initiative program in Pakistan which linked communities / beneficiaries with health facilities throughout the country. Approximately, 110,000 Lady Health Workers (LHWs) were recruited throughout country including 23,185 LHWs for Sindh Province (MoH, 2011).

The program was devolved to province after enactment of $18^{\text {th }}$ Constitutional Amendment in 2010. The purpose was to promote awareness and community participation and to provide 
preventive, curative and rehabilitative services to the target population like female mothers and children with focus on family planning and primary healthcare. The program also envisaged enhancement in immunization of children ageing 12-23 months and ensuring their complete vaccination. It focused on provision of Maternal \& Child Healthcare $(\mathrm{MCH})$ by taking steps to reduce Infant Mortality Rate (IMR) from 85 to 55/1000 Live Births (LBs) and reduction in Maternal Mortality Rate (MMR) from 400 to 180/100,000 Live Births. It also focused on improving food and nutritional requirements for mothers \& children (GoS, 2018).

Each LHW is attached with a government health facility like rural health centre (RHC) or a basic health unit (BHU) in community, where she receives training, stipend and medical supplies. They register population in their community area and target groups including pregnant mothers Each LHW is responsible for approximately 1,000 people within a catchment area of 200 houses. They work directly out from their homes, which are commonly called "health hubs" and are selected from that rural community and trained to provide healthcare services to that community. The LHW must have recommendation from the community, has middle/matric school education, a local resident, preferably married, and at least eighteen years of age. The LHWs visit households to create awareness on reproductive health, nutrition, facilitate registration of births and deaths, distribution of medicines for family planning and assist in immunizing children as per national schedule. LHWs advise pregnant clients to seek ANC services in the public sector health facilities, even though care in the private sector is considered to be of higher quality. LHWs coordinate with traditional birth attendants and midwives to ensure that mothers receive adequate healthcare. For complicated conditions, LHWs are trained to refer patients to nearby hospitals or clinics (Ministry of Health Pakistan, 2011).

\section{LITERATURE REVIEW}

The studies show that Pakistan has the highest maternal mortality ratios (MMR) in South Asia at 178 per 100,000 live births. The infant mortality rate is 74 deaths per 1,000 live births, which is even higher in rural areas. The antenatal visits by pregnant mothers in fourth month of pregnancy were $33 \%$ only and about $35 \%$ mothers received 
no prenatal care as reported by WHO Pakistan Demographic and Health Survey (PDHS) 2018 (WHO, 2018). About 7.6 million children under five died annually in the world. Common reason highlighted was lack of awareness of target women. Skilled Birth Attendants (SBAs) assisted only 39\% of births, with significant disparities by rural-rural residence. About $34 \%$ of births took place in a health facility and $66 \%$ were home deliveries and among the home based deliveries only $7.6 \%$ were assisted by a skilled birth attendant (NIPS, 2008). Significant improvement has been seen by LHWP intervention, the data obtained from the program office Sindh depicts remarkable reduction in MMR due to healthcare provision by SBAs. Moreover, country is striving hard to achieve the United Nation Sustainable Development Goals (SDGs) by 2030.

The maternal deaths can only be prevented by right decision- making to get proper medical advice (if birth complications are noticed), utilizing services of skilled birth attendant during labor and ensuring availability of emergency care \& referral to quality healthcare facility (Campbell \& Graham, 2016). The antenatal care (ANC) in ante-partum period prevents complications by proper management and saves life of mother and child (Amin, Shah and Becker, 2010). The conduct of routine ANC helps client in birth preparedness, identify complications and prevent complicated pregnancies, particularly in rural areas where education level is low. ANC has been found to be important determinant of safe delivery and is positively related with uptake of postnatal healthcare services thus ensures reduction in maternal mortality (Andersen and Newman, 2007). ANC visits provide mothers with opportunities to obtain preventative health services like immunizations against neonatal tetanus, prevention of malaria, HIV counseling and lab testing such as blood and urine tests (WHO \& UNICEF, 2003). The immunization of pregnant women against tetanus is one of the effective methods of reducing neonatal tetanus mortality rates and occurrence of maternal tetanus. In 2008, about 59,000 newborns died worldwide due to neonatal tetanus and the cases reported alone in Pakistan numbered 508 (Arif and Farooq, 2011). In Pakistan, over $65 \%$ of the population live in rural areas, where there is absence of community health worker, lack of infrastructure, poor road 
conditions, absence of transport, and hilly and desert terrains which reduce women's access to services (NIPS, 2008).

Pakistan's public health sector has a three-tiered service delivery system composed of primary, secondary and tertiary care. Presently there are approximately 13,051 primary care facilities and 965 tertiary and secondary hospitals. The population-to-health facility ratios has shown decline from 28,971:1 to 12,357:1, number of trained health workers has remained low with just 1.4 nurses, midwives, and doctors per 1,000 people compared to an estimated 2.28 required for population's basic needs. There are limited career advancement opportunities for health workforce, lack of human resources, poor working environment and inequitable resource allocation in public health sector. Thus, most of the population uses services from the private sector, which accounts for 70 to $80 \%$ of total healthcare delivery. Moreover, the government is trying to expand access and improve health facilities, regulating private sector, promoting gender equity and reducing professional and managerial deficiencies in the district health system (Atun, 2014).

Study conducted showed that Lady Health Worker (LHW) program aimed to provide door step reproductive health services was constrained due to women's accessibility and mobility to health care facilities. Thus program could not achieve its optimal results in providing primary healthcare services to underserved communities. Qualitative data showed that LHWs restricted mobility into the area occupied by unrelated males was the main cause. Caste-based village hierarchies further discouraged visits beyond biradari boundaries and additionally the home visits were also not undertaken optimally. The findings suggested that LHW performance was constrained due to gender biases, caste-based hierarchies and LHW's poor and low caste socio-economic factors (Mumtaz, Z., et.al., 2013). A study was conducted to see how effectively motivated LHW can perform more actively in tuberculosis cases in Sindh using both internal and external sources of motivation. It was found that internal drivers of motivation like religious rewards and social recognition were more important. The LHWs indicated that financial incentives were less important than other sources of motivation and were usually not perceived as rewards 
for their performance. It was concluded that internal motivation which is intrinsic and religious in Pakistan played important role in performance of LHWs (Khan, Mehboob and Rahman, 2019).

Government introduced a community based birth attendants, the community midwives (CMW) who were trained to conduct homebased deliveries. A qualitative research was conducted in one rural district namely Attock of Pakistan along with focus group discussions with CMWs and other community based health workers such as LHWs and LHSs, focusing on the role of CMWs in the existing primary health care system. Study found that they were inadequately trained, lacked resources for service delivery in their catchment areas and lacked integration in district health system. The CMWs have potential to play important role in reducing maternal mortality and in improving child healthcare if they are provided with adequate training and facilitated by health department (Sarfaraz and Hamid, 2014). Research also showed that the use of mobile phones by lady health supervisors was seen important in improving the quality of supervision in Badin District of Sindh Province. Again a capacity building project in Mirpurkhas district of rural Sindh, revealed quit a positive impact. Resultantly, with support from a donor funded project, Umeed-e-Nau Sindh government upgraded the curriculum for lady health supervisors and incorporated the use of mobile phones for providing the quality preventive healthcare services delivered by lady health workers (Portela and Qazi, 2018).

\section{DATA COLLECTION AND ANALYSIS}

The purpose of study was to analyze the impact of LHWP on maternal health services which is determined by two dependent variables (i) provision of antenatal care, and (ii) Toxoid injection to pregnant mothers during pregnancy, in rural districts of Sindh. First hand information in the form of three years (2017-2019) secondary data was collected from Sindh LHW Program office Hyderabad. The data was analyzed to see the impact on the use of maternal health service by analyzing the variables like Antenatal care and injection of Tetanus Toxoid to pregnant mothers aging from 19 to 49 years. The secondary data from Pakistan Demographic and Health Survey for 2017-18 was also analyzed to see the impact independently complementing the results of Sindh LHWP office data. 
The data obtained from program office of Sindh from 2017 to 2019 depicts significant improvement in maternal health care indicators. Table-1 shows that about 89 percent women were given antenatal care resultantly reduction in maternal deaths was noticed.

TABLE-1

\begin{tabular}{|c|c|c|c|c|c|c|c|c|c|}
\hline District & $\begin{array}{c}\text { \# of } \\
\text { women } \\
\text { delivered } \\
\text { with 4+ } \\
\text { ANC }\end{array}$ & $\begin{array}{c}\text { Total } \\
\text { deliveries }\end{array}$ & $\begin{array}{c}\% \\
\text { Deliveries } \\
\text { with 4+ } \\
\text { ANC }\end{array}$ & $\begin{array}{c}\text { \# of } \\
\text { women } \\
\text { delivered } \\
\text { with 4+ } \\
\text { ANC }\end{array}$ & $\begin{array}{c}\text { Total } \\
\text { deliveries }\end{array}$ & $\begin{array}{c}\% \\
\text { Deliveries } \\
\text { with 4+ } \\
\text { ANCs }\end{array}$ & $\begin{array}{c}\text { \# of } \\
\text { women } \\
\text { delivered } \\
\text { with 4+ } \\
\text { ANCs }\end{array}$ & $\begin{array}{c}\text { Total } \\
\text { deliveries }\end{array}$ & $\begin{array}{c}\% \\
\text { Deliveri } \\
\text { es with } \\
4+ \\
\text { ANCs }\end{array}$ \\
\hline & \multicolumn{3}{|c|}{2017} & \multicolumn{3}{|c|}{2018} & \multicolumn{3}{|c|}{2019 (6 MONTHS) } \\
\hline Badin & 17613 & 19382 & 91 & 18596 & 20910 & 89 & 9497 & 10437 & 91 \\
\hline Dadu & 18185 & 19176 & 95 & 18859 & 19836 & 95 & 8668 & 9226 & 94 \\
\hline Hyderabad & 17682 & 19530 & 91 & 17158 & 18771 & 91 & 8037 & 8967 & 90 \\
\hline Sujawal & 3745 & 4693 & 80 & 3205 & 3765 & 85 & 1355 & 1424 & 95 \\
\hline Jamshoro & 9281 & 10287 & 90 & 9106 & 9952 & 91 & 4146 & 4487 & 92 \\
\hline Tando Allahyar & 10582 & 12735 & 83 & 10714 & 12413 & 86 & 5419 & 6237 & 87 \\
\hline Thatta & 6870 & 7245 & 95 & 6274 & 8804 & 71 & 3075 & 3404 & 90 \\
\hline Matiari & 9130 & 9509 & 96 & 9071 & 9500 & 95 & 4402 & 4582 & 96 \\
\hline T M Khan & 6986 & 8275 & 84 & 6952 & 8200 & 85 & 3411 & 4209 & 81 \\
\hline Khi West & 9285 & 9658 & 96 & 9533 & 9794 & 97 & 5120 & 5304 & 97 \\
\hline Karachi East & 2852 & 2980 & 96 & 3316 & 3442 & 96 & 1860 & 1943 & 96 \\
\hline Korangi & 6278 & 6561 & 96 & 6263 & 6580 & 95 & 3281 & 3497 & 94 \\
\hline Khi Central & 4376 & 4392 & 99.6 & 4497 & 4636 & 97 & 2555 & 4647 & 55 \\
\hline Khi South & 2445 & 2541 & 96 & 2486 & 2486 & 100 & 1405 & 1471 & 96 \\
\hline Malir & 8824 & 9158 & 96 . & 9061 & 9379 & 97 & 4771 & 5059 & 94 \\
\hline Jacobabad & 7312 & 8786 & 83 & 6861 & 7880 & 87 & 3339 & 3736 & 89 \\
\hline Larkana & 10783 & 11702 & 92 & 13308 & 14180 & 94 & 5872 & 6276 & 94 \\
\hline Shikarpur & 9829 & 9829 & 100 & 11088 & 12475 & 89 & 5545 & 5545 & 100 \\
\hline Kamber & 8856 & 10544 & 84 & 11556 & 12814 & 90 & 5915 & 6218 & 95 \\
\hline Kashmore & 2684 & 4098 & 65 & 2552 & 4760 & 54 & 1336 & 2085 & 64 \\
\hline Khairpur & 25504 & 28636 & 89 & 26443 & 29257 & 90 & 12185 & 13366 & 91 \\
\hline $\mathrm{N}^{\prime}$ Feroze & 20160 & 20190 & 100 & 18227 & 21232 & 86 & 8295 & 9501 & 87 \\
\hline S. Benazirabad & 20498 & 21513 & 95 & 19562 & 21030 & 93 & 9437 & 10259 & 92 \\
\hline Sukkur & 4766 & 7231 & 66 & 10401 & 13081 & 80 & 5353 & 5847 & 92 \\
\hline Ghotki & 13009 & 15341 & 85 & 14684 & 16338 & 90 & 6341 & 7018 & 90 \\
\hline Mirpurkhas & 12555 & 13694 & 92 & 12951 & 14408 & 90 & 6678 & 7274 & 92 \\
\hline Sanghar & 19222 & 21348 & 90 & 19594 & 21460 & 91 & 9553 & 10173 & 94 \\
\hline Tharparkar & 10071 & 13435 & 75 & 10397 & 13720 & 76 & 6320 & 7572 & 83 \\
\hline Umerkot & 12411 & 15078 & 82 & 14006 & 16622 & 84 & 7048 & 9147 & 77 \\
\hline Average $\%$ & 311794 & 347547 & 89 & 326721 & 367725 & 88.5 & 160219 & 178911 & 89.5 \\
\hline
\end{tabular}

The Table-1 shows year wise and district wise status of total number of deliveries and the deliveries in which four or four plus Antenatal care visits for service were carried out to the ever married pregnant mothers aging between 19 to 49 years. The data shows that on average $89 \%$ women received antenatal care with a significant improvement in rural districts of Sindh.

The data from Pakistan Demographic and Health Survey 2017-

18 also showed improvement in provision of maternal health services to the target population. Figure-1 shows that antenatal care provided by skilled worker show remarkable increase from $26 \%$ in $1990-91$ to $86 \%$ in 2017-18. This data validates the data obtained from Sindh LHW Program. 


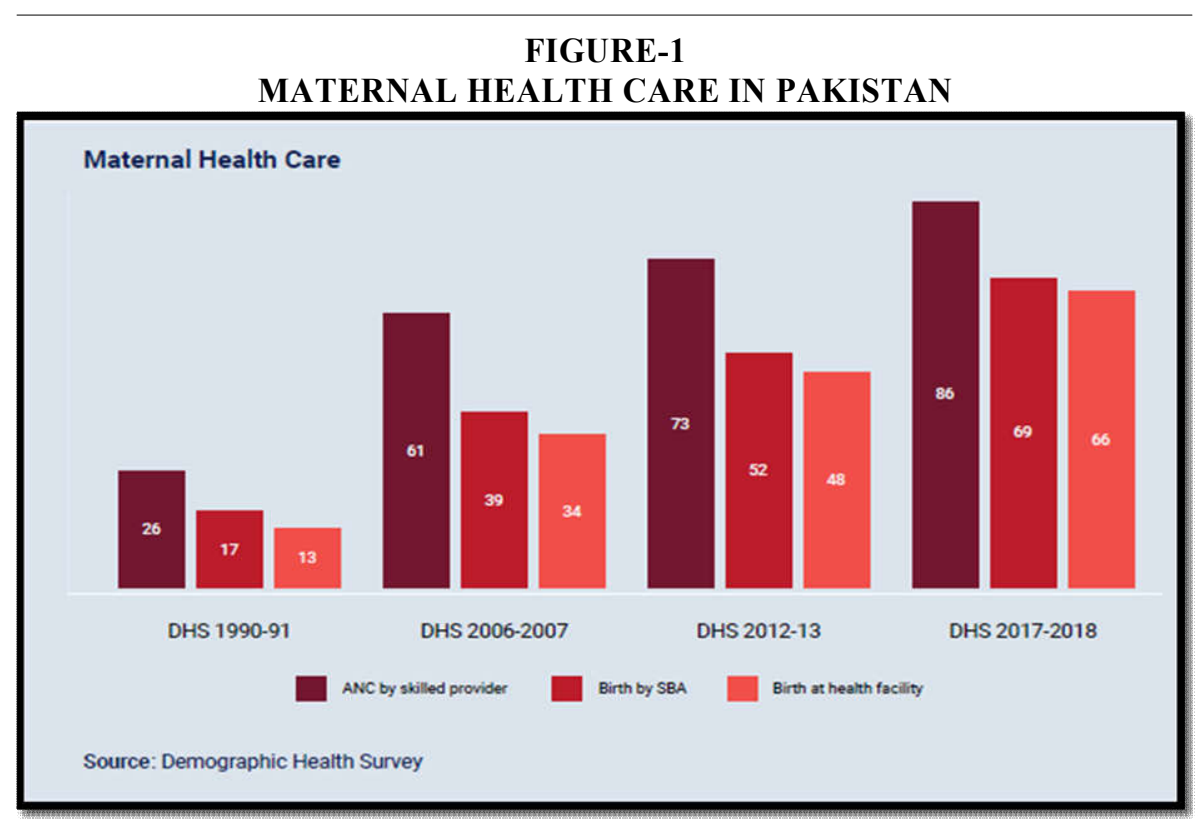

Source: Pakistan Demographic Health Survey 2017-18.

Similarly, the data obtained from Sindh LHW program office in following Table-2 shows the application of at least two Tetanus Toxoid injections to pregnant mothers during pregnancy. The intervention has shown vaccination of TT to pregnant mothers at improved percentage. The table shows year wise and district wise total number of deliveries and the delivery of mothers who were at least given two Tetanus Toxoid injections during their pregnancy. Data shows that $94 \%$ of women received TT injections in 2019 which show remarkable impact of the program. 
Biannual Research Journal Grassroots Vol.55, No.I: 145-158

\begin{tabular}{|c|c|c|c|c|c|c|c|c|c|c|}
\hline \multirow[t]{3}{*}{, } & \multicolumn{8}{|c|}{$\begin{array}{l}\text { TABLE-2 } \\
\text { TETANUS TOXOID VACCINATION (2TTS) TO PREGNANT WOMEN } \\
\text { BEFORE DELIVERY IN SINDH PROVINCE }\end{array}$} & \multirow{2}{*}{\multicolumn{2}{|c|}{ month data) }} \\
\hline & \multirow[b]{2}{*}{ District } & \multicolumn{3}{|c|}{2017} & \multicolumn{3}{|c|}{2018} & 2019 (6 month data) & & \\
\hline & & $\begin{array}{c}\text { Total } \\
\text { Deliveries }\end{array}$ & \begin{tabular}{c|c|} 
\# Women \\
Completed \\
TT before \\
\end{tabular} & $\%$ & $\begin{array}{c}\text { Total } \\
\text { Deliveries }\end{array}$ & $\begin{array}{l}\text { \# Women } \\
\text { Completed } \\
\text { TT before }\end{array}$ & $\%$ & $\begin{array}{c}\text { Total } \\
\text { Deliveries }\end{array}$ & $\begin{array}{l}\text { \# Women } \\
\text { Completed } \\
\text { TT before }\end{array}$ & $\%$ \\
\hline 1. & Badin & 19382 & 18665 & 96 & 20910 & 19470 & 93 & 10437 & 9833 & 94 \\
\hline 2 & Dadu & 19176 & 18198 & 95 & 19836 & 18875 & 95 & 9226 & 8673 & 94 \\
\hline 3 & Hyderabad & 38558 & 36863 & 96 & 40746 & 38345 & 94 & 19663 & 18506 & 94 \\
\hline 4 & Sujawal & 4693 & 3768 & 80 & 3765 & 3213 & 85 & 1424 & 1292 & 91 \\
\hline 5 & Jamshoro & 10287 & 9740 & 95 & 9952 & 9503 & 96 & 4487 & 4264 & 95 \\
\hline 6 & Tando Allahyar & 14980 & 13508 & 90 & 13717 & 12716 & 93 & 5911 & 5556 & 94 \\
\hline 7 & Thatta & 7245 & 7059 & 97 & 8804 & 6491 & 73 & 3404 & 3086 & 91 \\
\hline 8 & Matiari & 9509 & 9188 & 97 & 9500 & 9152 & 96 & 4582 & 4426 & 97 \\
\hline 9 & T. M Khan & 16754 & 16247 & 97 & 18304 & 15643 & 85 & 7986 & 7512 & 94 \\
\hline 10 & Karachi West & 9658 & 9274 & 96 & 9794 & 9565 & 98 & 5304 & 5104 & 96 \\
\hline 11 & Karachi East & 2980 & 2885 & 97 & 3442 & 3338 & 97 & 1943 & 1863 & 96 \\
\hline 12 & Korangi & 12638 & 12159 & 96 & 13236 & 12903 & 98 & 7247 & 6967 & 96 \\
\hline 13 & Karachi Central & 4392 & 4325 & 98 & 4636 & 4474 & 97 & 4647 & 4526 & 97 \\
\hline 14 & Karachi South & 2541 & 2491 & 98 & 2486 & 2630 & 101 & 1471 & 1414 & 96 \\
\hline 15 & Malir & 9158 & 8360 & 91 & 7122 & 7104 & 100 & 5059 & 4519 & 89 \\
\hline 16 & Jacobabad & 8786 & 7905 & 90 & 7880 & 7154 & 91 & 3736 & 3513 & 94 \\
\hline 17 & Larkana & 11702 & 11288 & 96 & 14180 & 13589 & 96 & 6276 & 5922 & 94 \\
\hline 18 & Shikarpur & 20488 & 19193 & 94 & 22060 & 20743 & 94 & 10012 & 9435 & 94 \\
\hline 19 & Kamber & 10544 & 9288 & 95 & 12814 & 11752 & 92 & 6218 & 5874 & 94 \\
\hline 20 & Kashmore & 4738 & 4465 & 94 & 4760 & 4012 & 84 & 2085 & 1991 & 95 \\
\hline 21 & Khairpur & 28636 & 26628 & 93 & 17574 & 15764 & 90 & 13366 & 12456 & 93 \\
\hline 22 & Naushero & 22623 & 20848 & 92 & 21232 & 20485 & 95 & 9501 & 9122 & 96 \\
\hline 23 & S. Benazirabad & 21513 & 20758 & 97 & 21030 & 19654 & 94 & 10259 & 9461 & 92 \\
\hline 24 & Sukkur & 7231 & 4777 & 66 & 42262 & 40139 & 95 & 5847 & 5440 & 93 \\
\hline 25 & Ghotki & 15341 & 14672 & 96 & 16338 & 15654 & 96 & 7018 & 6747 & 96 \\
\hline 26 & Mirpurkhas & 13694 & 12849 & 94 & 14408 & 13302 & 92 & 7274 & 6810 & 94 \\
\hline 27 & Sanghar & 21348 & 19660 & 92 & 30746 & 28956 & 94 & 10173 & 9678 & 95 \\
\hline 28 & Tharparkar & 13611 & 13325 & 98 & 13720 & 12612 & 92 & 8372 & 7353 & 88 \\
\hline 29 & Umerkot & 15078 & 14454 & 96 & 16622 & 15724 & 95 & 9147 & 7906 & 86 \\
\hline$A v$ & rage $\%$ & 397284 & 372840 & 93 & 441876 & 412962 & 93 & 202075 & 189249 & 94 \\
\hline
\end{tabular}

Further, remarkable reduction in Maternal Mortality Rate (MMR) was seen after analyzing the data obtained from the LHW program office Sindh for 2017-2019. The data in table-3 shows year wise number of live births and number of maternal deaths. The 175 maternal deaths were reported during 2019 against 174901 live birth deliveries. The MMR 2019 calculated by direct method i.e dividing maternal deaths with live births and multiplying by 100,000 reveal ratio of 100 maternal deaths per 100,000 live births which has been remarkably reduced due to this program intervention. 
Biannual Research Journal Grassroots Vol.55, No.I: 145-158

\begin{tabular}{|c|c|c|c|c|c|c|c|c|c|}
\hline \multirow[b]{3}{*}{ District } & \multicolumn{9}{|c|}{$\begin{array}{l}\text { TABLE-3 } \\
\text { DISTRICT-WISE MATERNAL MORTALITY RATE }(2017-2019) \text { IN SINDH }\end{array}$} \\
\hline & \multicolumn{3}{|c|}{2017} & \multicolumn{3}{|c|}{2018} & \multicolumn{3}{|c|}{2019 (6 months) } \\
\hline & $\begin{array}{l}\text { \# Maternal } \\
\text { Deaths }\end{array}$ & $\begin{array}{l}\text { \# Live } \\
\text { Births }\end{array}$ & MMR & $\begin{array}{l}\text { \# Maternal } \\
\text { Deaths }\end{array}$ & $\begin{array}{l}\text { \# Live } \\
\text { Births }\end{array}$ & $\begin{array}{l}\text { M } \\
\text { MR }\end{array}$ & $\begin{array}{l}\text { \# Maternal } \\
\text { Deaths }\end{array}$ & $\begin{array}{l}\text { \# Live } \\
\text { Births }\end{array}$ & MMR \\
\hline Tando Allahyar & 26 & 12402 & 210 & 16 & 7678 & 208 & 9 & 3642 & 247 \\
\hline Umerkot & 26 & 14621 & 178 & 23 & 11951 & 192 & 8 & 4346 & 184 \\
\hline Larkana & 19 & 11559 & 164 & 25 & 14093 & 177 & 6 & 3280 & 183 \\
\hline Ghotki & 23 & 14923 & 154 & 15 & 9217 & 163 & 11 & 6174 & 178 \\
\hline Tando M Khan & 12 & 8067 & 149 & 26 & 19582 & 131 & 6 & 3433 & 175 \\
\hline Tharparkar & 18 & 13132 & 137 & 14 & 12067 & 116 & 10 & 6067 & 165 \\
\hline Hyderabad & 25 & 18920 & 132 & 11 & 9703 & 113 & 7 & 4428 & 158 \\
\hline Jamshoro & 13 & 9962 & 131 & 23 & 20384 & 113 & 11 & 7127 & 154 \\
\hline Matiari & 10 & 9210 & 109 & 18 & 18305 & 98 & 8 & 5361 & 149 \\
\hline Sanghar & $21^{\circ}$ & 20725 & 101 & 6 & 6488 & 92 & 13 & 8850 & 147 \\
\hline Dadu & 19 & 18846 & 101 & 3 & 3367 & 89 & 7 & 5219 & 134 \\
\hline S. Benazirabad & 21 & 21206 & 99 & 12 & 13476 & 89 & 12 & 10123 & 119 \\
\hline Kashmore & 4 & 4068 & $9 \hat{8}$ & 14 & 16079 & 87 & 11 & 10022 & 110 \\
\hline Karachi West & 9 & 9535 & 94 & 8 & 9215 & 88 & 2 & 1905 & 105 \\
\hline Jacobabad & 8 & 8572 & 93 & 7 & 8276 & 85 & 5 & 6066 & 82 \\
\hline Karachi South & 2 & 2494 & 80 & 3 & 3554 & 84 & 6 & 7441 & 81 \\
\hline N'Feroze & 14 & 19811 & 71 & 24 & 28759 & 83 & 7 & 8744 & 80 \\
\hline Badin & 13 & 18993 & 68 & 10 & 12974 & 77 & 3 & 4068 & 74 \\
\hline Khairpur & 19 & 28179 & 67 & 6 & 7950 & 75 & 4 & 5768 & 69 \\
\hline Kamber & 6 & 10464 & 57 & 11 & 15977 & 69 & 8 & 13133 & 61 \\
\hline Sujawal & 2 & 4320 & 46 & 14 & 20889 & 67 & 6 & 9951 & 60 \\
\hline Karachi Central & 2 & 4345 & 46 & 9 & 14064 & 64 & 5 & 9263 & 54 \\
\hline Mirpurkhas & 6 & 13520 & 44 & 10 & 20735 & 48 & 4 & 9079 & 44 \\
\hline Malir & 4 & 9014 & 44 & 6 & 12646 & 47 & 3 & 6902 & 43 \\
\hline Thatta & 3 & 7158 & 42 & 1 & 2432 & 41 & 2 & 4960 & 40 \\
\hline Shikarpur & 2 & 9744 & 21 & 8 & 20827 & 38 & 1 & 4607 & 22 \\
\hline Korangi & 1 & 6460 & 15 & 3 & 9679 & 31 & 0 & 2078 & 0 \\
\hline Karachi East & 0 & 2955 & 0 & 0 & 4680 & 0 & 0 & 1421 & 0 \\
\hline \multirow[t]{2}{*}{ Sukkur } & 0 & 7222 & 0 & 0 & 4605 & 0 & 0 & 1443 & 0 \\
\hline & 328 & 340427 & & 326 & 359653 & & 175 & 174901 & \\
\hline
\end{tabular}

Source: Sindh LHW Program 2019.

The secondary data about Maternal Mortality Ratio obtained from Pakistan Maternal Mortality Survey 2019 is depicted in the following Table-4 which shows that Maternal Mortality Ratio (MMR) i.e. live births in households divided by maternal deaths and multiplied by 100,000 in Pakistan is 189 maternal deaths per 100,000 live births. The MMR is higher in rural areas i.e 203 per 100,000 live births as compared to urban areas i.e. 159 maternal deaths per 100,000 live births. In Sindh MMR has been estimated as 237 maternal deaths per 100,000 live births. 


\begin{tabular}{|c|c|c|c|}
\hline \multicolumn{4}{|c|}{$\begin{array}{l}\text { TABLE-4 } \\
\text { ESTIMATED MATERNAL MORTALITY RATIO } \\
\text { IN PROVINCES OF PAKISTAN -2019 }\end{array}$} \\
\hline \multicolumn{4}{|c|}{$\begin{array}{l}\text { Maternal mortality ratios for the } 3 \text { years preceding the survey, by residence } \\
\text { and region, Pakistan MMS } 2019\end{array}$} \\
\hline & $\begin{array}{c}\text { Maternal } \\
\text { deaths }\end{array}$ & Live births & $\begin{array}{c}\text { Maternal } \\
\text { mortality ratio }\end{array}$ \\
\hline $\begin{array}{l}\text { Residence } \\
\text { Urban } \\
\text { Rural }\end{array}$ & $\begin{array}{l}32 \\
88\end{array}$ & $\begin{array}{l}20,333 \\
43,290\end{array}$ & $\begin{array}{l}159 \\
203\end{array}$ \\
\hline $\begin{array}{l}\text { Region } \\
\text { Punjab } \\
\text { Sindh } \\
\text { Khyber Pakhtunkhwa } \\
\text { Balochistan }\end{array}$ & $\begin{array}{l}52 \\
33 \\
23 \\
13\end{array}$ & $\begin{array}{r}31,753 \\
13,786 \\
14,075 \\
4,010\end{array}$ & $\begin{array}{l}165 \\
237 \\
161 \\
317\end{array}$ \\
\hline Total ${ }^{4}$ & 120 & 63,623 & 189 \\
\hline $\begin{array}{l}\text { Azad Jammu and Kashmir } \\
\text { Gilgit Baltistan }\end{array}$ & $\begin{array}{r}9 \\
12\end{array}$ & $\begin{array}{l}8,501 \\
7,712\end{array}$ & $\begin{array}{l}108 \\
162\end{array}$ \\
\hline \multicolumn{4}{|c|}{$\begin{array}{l}\text { A maternal death is defined as the death of a woman while pregnant or } \\
\text { during childbirth or within } 42 \text { days after delivery, for which there was a verbal } \\
\text { autopsy which was classified as being either a direct or indirect maternal } \\
\text { death } \\
2 \text { Punjab includes ICT } \\
3 \text { Khyber Pakhtunkhwa includes the merged districts of former FATA } \\
4 \text { Total excludes Azad Jammu and Kashmir and Gilgit Baltistan }\end{array}$} \\
\hline
\end{tabular}

Source: Pakistan Maternal Mortality Survey, 2019.

The comparison of actual data obtained from Sindh LHW program office and estimated data of Pakistan MMR Survey 2019 reveal remarkable decline in the MMR indicator showing that due to intervention of Sindh LHW program, the maternal health care service utilization has increased causing significant reduction in maternal mortality ratio from estimated 237 to 100 maternal deaths per 100,000 live birth in Sindh.

\section{CONCLUSION AND RECOMMENDATIONS}

In this study we analyzed the impact of Lady Health Worker program on use of maternal health service by target population who are married women aging between 19 to 49 years in Sindh province. The maternal healthcare depends on antenatal care and the injection of Tetanus Toxoid vaccination to pregnant mothers. For this purpose empirical evidence was drawn based on the secondary data provided by the Sindh LHW program office located at Hyderabad and other secondary sources to reach at conclusion. After analyzing the data obtained from various sources following conclusion was drawn. The presence of a lady health worker in a community has 
a remarkable positive influence on uptake of maternal health services which is determined by antenatal care and tetanus toxoid injection to pregnant mothers, resulting into significant decline in MMR and IMR.

\section{ANTENATAL CARE}

The Secondary data obtained from Sindh LHW program for Years 2017 to 2019 pertaining to all districts of Sindh province revealed remarkable impact of antenatal care visits carried out by the lady health workers in areas of their assignment. On the average $89 \%$ of total number of clients had carried out at least four antenatal care visits during their pregnancy assisted by LHW of that area. This was compared with the secondary data from Pakistan Demographic and Health Survey 2017-18 where in entire country the antenatal care visits were shown as $76 \%$. Thus a remarkable improvement in uptake of healthcare service was seen showing positive impact of LHW program on clients.

\section{TETANUS TOXOID INJECTION AND MATERNAL MORTALITY RATE}

The second determinant of uptake of maternal healthcare service is application of at least two tetanus toxoid injections to mothers during pregnancy to prevent maternal tetanus. The secondary data obtained from Sindh LHW program office for years 2017 to 2019 pertaining to all districts of Sindh province revealed that out of total deliveries $94 \%$ women received two injections of tetanus toxoid, indicating that deaths due to maternal tetanus have been reduced significantly. This is evident from Maternal Mortality ratio of Sindh province where data from Sindh LHW program for 2019 show significant decline in MMR which is 100 maternal deaths per 100,000 live births. This is much lower as compared to estimates from Pakistan Maternal Mortality Survey 2019, which shows MMR for Sindh province as 237 maternal deaths per 100,000 live births. This remarkable decline in maternal death ratio reveals positive impact on utilization of maternal health care service by target population in Sindh province and provides an empirical evidence that under Sindh LHW program intervention the performance of lady health workers has produced positive impact on uptake of maternal health care services. 
The role of LHWs in providing maternal healthcare to target women, especially in rural areas which lack facilities and resources is recognizable. The areas where LHWs are performing their duties has shown improvement in uptake of primary healthcare services by communities. Currently in Sindh provinces this program has catered services to $46 \%$ areas where LHWs are providing services (SLHW, 2019). There is dire need to expand the program to the areas which are still not covered by this program. This is due to shortage of LHWs as against the sanctioned strength of 22576; only 20988 have been deployed with 1588 positions still lying vacant (SLHW, 2019). The provision of medicines, hospital supplies and checking kits to LHWs is also important along with provision of pucca (paved) road infrastructure for easy access and mobility of service provider to target population and government health facility. The workers need to be given bonuses and incentives to retain them besides provision of security while performing visits in far flung areas by involving local community people and police.

\section{REFERENCES}

Amin R, Shah N, Becker S. (2010) Socioeconomic factors differentiating maternal and child health-seeking behavior in rural Pakistan: A crosssectional analysis. Int. J. Equity Health, 2010, 9:9.

Andersen. R.M., Newman, J.F. (2007). Societal and individual determinants of medical care utilization in the United States. Milbank Memorial Fund Quarterly. 51:95-124.

Arif, G. M. and Farooq Shujaat (2011). Poverty Inequality and Unemployment in Pakistan. Backgroung study for IDB Group MCPS Document for Pakistan. Dhul-Qa'dah 1432H.

Atun, Rifat; Nina Zhu \& Elizabeth Allen (2014). Harvard School of Public Health, Lady Health Workers in Pakistan-Improving access to health care for rural women and families.

Campbell O.M. \& Graham W.J. (2016). Strategies for reducing maternal mortality: getting on with what works. The Lancet 10/713;368(9543):1284-1299.

GoS (2018). LHW Program, Health Department, Hyderabad.

Khan, M.S., Mehboob, N. Rahman-Shepherd, A. (2019). What can motivate Lady Health Workers in Pakistan to engage more actively in tuberculosis case-finding?. BMC Public Health 19,999. https://doi.org/10.1186/ $\underline{\text { s12889-019-7326-8 }}$ 
Ministry of Health. (2013). PC-1 National Programme for Family Planning and Primary Health Care "The Lady Health Workers Programme 2003-2008, Islamabad: Government of Pakistan.

Mumtaz Z, Salway S, Nykiforuk C, Bhatti A, Ataullahjan A. (2013). The role of social geography on Lady Health Workers' mobility and effectiveness in Pakistan, Soc.Sci Med. August, Pp.48-57. doi:10.1016/j.socscimed. 2013.05.007.

National Institute of Population Studies (2008). Government of Pakistan.

Pakistan Demographic and Heath Survey (PDHS). WHO 2006-07 and 2017-18.

Pakistan Demographic and Heath Survey (PDHS). 2006-07 and 2017-18. Government of Pakistan.

Pakistan Economic Survey 2017-18. Finance Division, Government of Pakistan.

Pakistan Maternal Mortality Survey (2019). Key Indicators Report, National Institute of Population Studies Islamabad, Pakistan.

Portela, Anayda and Qazi Shamim Ahmad (2018). Implementation research for maternal, newborn and child health, Acta Paediatrica: Nurturing the Child, Vol.107, Issue S471, https://doi.org/10.1111/apa.14641

Sarfraz M, Hamid S. (2014). 'Challenges in delivery of skilled maternal care experiences of community midwives in Pakistan'. BMC Pregnancy Child Birth. February 5:59. doi:10.1186/1471-2393-14-59.

United Nations (2011). Child Mortality Report, Estimates Developed by the UN Inter-Agency Group for Child Mortality, United Nations. 